\title{
Células Dendríticas (CDs) diferenciadas a partir de Monocitos humanos como herramienta para el estudio de agentes antileishmaniales
}

\author{
Diana Granados ${ }^{1,2}$, Gabriela Delgado' \\ 1. Grupo de Investigación en Inmunotoxicología, Departamento de Farmacia, Facultad de Ciencias, \\ Universidad Nacional de Colombia \\ 2. Programa Doctoral en Biociencias, Facultad de Ingeniería, Universidad de la Sabana.
}

Correspondencia: Igdelgadom@unal.edu.co

Recibido:13-11-08 / Aceptado: 27-11-08

\begin{abstract}
Resumen
Las células dendríticas son consideradas potentes células presentadoras de antígeno, fundamentales para el inicio y desarrollo de una respuesta inmunitaria efectiva frente a diversos agentes infecciosos. El estudio de la interacción parásito-células dendríticas, es esencial para la evaluación y desarrollo de nuevas estrategias terapéuticas profilácticas capaces de controlar de una manera segura y efectiva el agente patógeno, si se tiene en cuenta que diferentes agentes patógenos (ej: parásitos perteneciente al genero Leishmania) pueden afectar la maduración y función de las células dendríticas, como uno de los principales mecanismos de evasión de la respuesta.

En el presente estudio, nosotros determinamos que las células dendríticas derivadas de monocitos de sangre periférica humana diferenciadas luego de 72 horas de cultivo en presencia de interleuquina 4 y factor estimulador de colonias granulocito/macrófago, pueden ser utilizadas exitosamente para la evaluación de la actividad anti-leishmanial e inmuno-moduladora de nuevas formulaciones terapéuticas para el control de la leishmaniosis.

Palabras clave: células dendriticas, citoquinas, interleuquinas, leishmaniasis, monocitos.
\end{abstract}

\begin{abstract}
Dendritic cells from human monocytes: As a tool to study antileishmanials agents

Dendritic cells, considered as powerful antigen presenting cells, are fundamental fir the beginning and development of an effective immune response against diverse infections agents. The study of interaction between dendritic cells and parasites is essential for the evaluation and development of new prophylactic and therapeutics strategies able to control the pathogenic agent in a safe and effective way. This is important when considering that different pathogenic agents (e.g. Leishmania parasites) can affect the maturation process and dendritic cells function, as an effective mechanism to evade the immune response. In this study, it was determined that dendritic cells differentiated from human peripheral blood monocytes (after 72 hours culture in presence of 4 interleukin and granulocyte/macrophage colonies stimulating factor) can successfully be used for evaluation of anti-leishmanial activity and immunomodulator effect of new therapeutics formulations for leishmaniasis control.

Key Words: cytokines, dendritic cells, interleukin, leishmaniasis, monocytes.
\end{abstract}




\section{Introducción}

La leishmaniosis es una enfermedad producida por especies de protozoarios pertenecientes al género Leishmania (L). Esta enfermedad es endémica en 88 países alrededor del mundo, por lo que la Organización Mundial de la Salud (OMS) la ha catalogado un problema de salud pública (1). Cada año se reportan en el mundo de 1 a 1,5 millones de casos nuevos de leishmaniosis cutánea, y cerca de 500,000 de la forma visceral.

Para el año 2007, en Colombia se notificaron 13,385 casos, de los cuales el $98,9 \%$ correspondían a la forma cutánea, el $0,6 \%$ a la forma mucosa y el $0,41 \%$ a la forma visceral (2). Desde el punto de vista epidemiológico en Colombia, las especies $L$. $(V)$ panamensis y $L$. $(V)$ braziliensis se encuentran asociadas con los casos clínicos de leishmaniosis cutánea y mucocutánea (3).

Diversos factores, como: (i) el desarrollo de resistencia a los fármacos; (ii) los efectos colaterales que desencadenan en el hospedero las formulaciones utilizadas para el tratamiento de la enfermedad y (iii) los altos costos que conlleva el tratamiento de esta patología, justifican la necesidad de buscar y desarrollar nuevas alternativas terapéuticas eficaces y seguras para el tratamiento de esta enfermedad en los países en vía de desarrollo (4).

En algunos casos las herramientas empleadas en el tamizaje de sustancias con propiedades antilesihmaniales no generan los resultados esperados, razón por la cual se hace necesaria la utilización de nuevas estrategias que permitan extrapolar fácilmente los resultados obtenidos in vitro a modelos animales y por ende a humanos. Por ejemplo, en muchos casos sustancias que aparentan ser promisorias en modelos in vitro empleando líneas murinas e incluso humanas, no muestran la misma eficacia cuando son evaluadas en modelos in vivo y menos cuando intentan ser analizadas en humanos en fases preclínicas de experimentación (5).

Sumado a lo anterior y teniendo en cuenta que los determinantes rasgos de susceptibilidad ó resistencia a la enfermedad derivan de las condiciones de inmunocompetencia del hospedero, se hace necesario el estudio de las propiedades antileishmaniales de una sustancia en el marco de un modelo que permita elucidar a su vez la capacidad inmunomoduladora de dicho candidato.
En los últimos años, el interés en la evaluación y caracterización de las células dendríticas (CDs) y su papel en la respuesta inmune frente a diversos agentes infecciosos, ha aumentado notablemente, debido a la evidencia acerca del papel que las CDs juegan en el inicio, desarrollo, dirección de la respuesta inmune y el control de patologías como la leishmaniosis (6).

Las CDs son potentes células presentadoras de antígeno (CPA), que se caracterizan por su extraordinaria capacidad para estimular células T "naive" (7). Se han logrado identificar tres subpoblaciones de CDs con características fenotípicas particulares: una localizada en la piel y órganos linfoides, conocidas como CDs intertisiciales, y las otras dos localizadas en la circulación, denominadas CDs de linaje mieloide CD11+CD8- y CDs plasmacitoides CD11-CD8+ (8). Diversos estudios han demostrado que las CDs tienen la capacidad de inducir diferentes tipos de respuesta inmune celular dependiendo del linaje y grado de maduración $(9,10)$.

Acorde a su estadio de maduración se han identificado dos grupos, las CDs inmaduras (CDi) que actúan como centinelas, caracterizándose por su alta capacidad de internalizar microorganismos por medio de procesos como la fagocitosis. Luego del encuentro de una CDi con señales de "alerta" [por ejemplo, productos derivado de patógeno (LPS) o citoquinas inflamatorias (TNF- $\alpha$ ), entre otras], se inducen una serie de cambios a nivel fenotípico y funcional, dando lugar en la mayoría de los casos a unas CDs de fenotipo maduro (11).

Las CDs maduras (CDm) se caracterizan por presentar una reducción en su capacidad fagocítica, sin embargo y a diferencia de las CDi, expresan altas cantidades de moléculas co-estimulatorias y otras moléculas involucradas en la presentación de antígenos (12). Luego de su activación, las CDs migran hacia los nódulos linfoides, donde presentan eficientemente los antígenos procesados derivados de patógeno, a los linfocitos $T$ en contexto de las moléculas del complejo mayor de histocompatibilidad (CMH) (13). Las CDs, así como otras células con actividad fagocítica tienen la capacidad de secretar diversas citoquinas implicadas en diversos procesos como la inflamación así como en el desarrollo de respuestas no especificas durante el inicio de la infección (14). 
Estudios han demostrado que la interacción CPApatógeno es fundamental en la modulación de la respuesta mediada por células. Es así como, el perfil de citoquinas en el que se genera la presentación antigénica, el grado de maduración de las CPAs, así como la expresión de las moléculas co-estimulatorias, son los eventos esenciales que dirigen la respuesta inmune efectora de células $T$ hacia un fenotipo determinado (susceptibilidad/resistencia natural a la infección) (15).

Diversos agentes patógenos, son capaces de alterar la maduración y función de las CDs con el fin de evadir la respuesta generada frente a ellos $(5,16)$. Estudios desarrollados en humanos y ratones frente a la infección por Leishmania, han permitido determinar algunos de los mecanismos celulares implicados en la resistencia y/o susceptibilidad frente a esta infección, uno de ellos, demuestra que las CDs juegan un papel esencial en el desarrollo, la regulación y el mantenimiento de la respuesta inmune frente a este patógeno (17). Específicamente se ha logrado establecer, que luego de la interacción parásito-CD se generan mediadores solubles pro-inflamatorios capaces de inducir una respuesta linfocitaria del fenotipo Th1 capaz de controlar la enfermedad (fenotipo resistente) (18).

En la actualidad existen diferentes metodologías para la obtención y/ó generación de CDs. La selección del método a utilizar para la obtención de las CDs puede tener un impacto en la habilidad de generar una respuesta in vitro cuyos resultados puedan extrapolarse con las respuestas generadas in vivo. En el presente estudio, determinamos que las CDs obtenidas luego de 72 horas de cultivo en presencia de interleuquina 4 (IL-4) y factor estimulador de colonias granulocito/macrófago (GM-CSF) derivadas de monocitos de sangre periférica humana, pueden ser utilizadas para la evaluación de la actividad anti-leishmanialinmunomoduladora de nuevos candidatos terapéuticos para el control de la leishmaniosis, como un modelo in vitro eficaz para el tamizaje de nuevas formulaciones.

\section{Materiales y Métodos}

\section{Medio de cultivo y reactivos:}

RPMI 1640 (Gibco BRL-life Technologies Inc, Grand Island, NY) fue utilizado como medio de cultivo, suplementado con 2mM L-glutamina (Gibco BRL-Life
Technologies Inc, Grand Island, NY), 1\% de aminoácidos no esenciales, $1000 \mathrm{U} / \mathrm{mL}$ penicilina, $0.1 \mathrm{mg} / \mathrm{mL}$ estreptomicina, $0.25 \mathrm{ug} / \mathrm{mL}$ amfotericina B (Sigma Chemical Co, St. Louis, MO), $24 \mathrm{mM}$ de bicarbonato de sodio (Sigma), $25 \mathrm{mM}$ de HEPES (Gibco). GMCSF (Leucomax, Essex Chimie SA, Lucerne) e IL-4 (Pharmingen, San Diego, CA, USA) fueron utilizadas para la diferenciación de monocitos a células dendríticas.

\section{Obtención de células mononucleares de sangre periférica (PBMCs):}

Las PBMCs fueron obtenidas a partir de $8 \mathrm{~mL}$ de sangre periférica heparinizada de individuos sanos por medio de la utilización de gradiente de densidad [FicollHypaque (Sigma Aldrich-St Louis. USA)]; 2 volúmenes de sangre diluida y 1 volumen de Ficoll-Hypaque, fueron centrifugados durante 30 minutos a 2800 r.p.m., la fracción de células blancas obtenida fue resuspendida en $8 \mathrm{~mL}$ de RPMI-1640 (Gibco BRL-life Technologies Inc, Grand Island, NY) y las células fueron lavadas tres veces con RPMI 1640 (Gibco-NY). El rendimiento y la viabilidad celular fueron determinadas utilizando la tinción con azul de tripán y conteo en cámara de Neubawer.

\section{Cultivo de células:}

Las PBMCs aisladas de sangre periférica fueron incubadas durante 2 horas a $37^{\circ} \mathrm{C}$ en $5 \%$ de CO2 y 90 $\%$ de humedad en cajas de 24 pozos estériles de plástico (para la evaluación de marcadores por Citometria de Flujo), para el ensayo de infección se utilizaron láminas (Nunc), de 8 pozos con RPMI 1640 suplementado con plasma autólogo. Luego se realizó un lavado con RPMI 1640 (Gibco-NY) con el fin de retirar las células no adherentes, de forma tal que los monocitos adherentes fueron incubados en RPMI 1640 suplementado con plasma autólogo (10\%) en presencia de $1000 \mathrm{U} / \mathrm{mL}$ de GM-CSF y $500 \mathrm{U} / \mathrm{mL}$ de IL-4 durante 72 horas a $37^{\circ} \mathrm{C}$ en $5 \%$ de $\mathrm{CO} 2$ y $90 \%$ de humedad, realizando cambios cada de medio cada día.

\section{Citometria de flujo y anticuerpos:}

Los siguientes anticuerpos fueron utilizados para el análisis de marcadores por citometria de flujo: clon L243, 
(anti-HLA-DR conjugado con PE (B.D. PharMingen-San Diego, CA, USA), clon DCN46 (anti-CD209 conjugado con FITC (B.D. PharMingen-San Diego, CA, USA), clon $\mathrm{M} \phi \mathrm{P} 9$ (anti-CD14 conjugado con PercP (B.D. PharMingen-San Diego, CA, USA), clon HB15e (antiCD83 conjugado con PE (B.D. PharMingen-San Diego, CA, USA) y clone L307.4 (anti-CD80 conjugado con PE (B.D. PharMingen-San Diego, CA, USA). Las células fueron evaluadas utilizando un citometro FACSCalibur (B.D. Biosciences-San Diego, CA, USA), y los datos fueron analizados usando CellQuest software (B.D. Biosciences-San Diego, CA, USA).

\section{Infección con promastigotes de Leishmania panamensis:}

CDi y monocitos adherentes fueron infectados con promastigotes de L. panamensis en una proporción de 35 parásitos por cada célula, durante 5 horas a $37^{\circ} \mathrm{C}$, en $5 \%$ de $\mathrm{CO} 2$. Al cabo de este tiempo, se realizaron 2 lavados con RPMI 1640 con el fin de retirar el parásito no internalizado. Posteriormente, se adicionó medio fresco suplementado con plasma autólogo, y luego de 24 horas de cultivo se recolectaron los sobrenadantes para la cuantificación de citoquinas asociadas con el proceso inflamatorio. Finalmente las láminas fueron lavadas con solución tamponada de fosfatos (PBS) 1X. Luego de fijarlas con Metanol (Chemi-S.A.), las láminas fueron coloreadas con Giemsa (Chemi-S.A.) para evaluar el porcentaje de células infectadas.

\section{Cuantificación de citoquinas:}

Los niveles de las interleuquinas (IL) IL-1 $\beta$, IL-6, IL-8, IL-10, IL-12 y Factor de Necrosis Tumoral (TNF- $\alpha$ ) fueron cuantificados mediante Cytometric Bead Array (CBA) (B.D. Biosciences-San Diego, CA, USA). $50 \mu \mathrm{L}$ de perlas de captura, $50 \mu \mathrm{L}$ del reactivo de detección de PE y $50 \mu \mathrm{L}$ de los sobrenadantes fueron mezclados. Simultáneamente, se montaron estándares de calibración para cada una de las citoquinas. Todas las mezclas fueron incubadas durante tres horas a temperatura ambiente, protegidas de la luz. Finalmente, las muestras fueron lavadas para remover el anticuerpo de detección - PE no unido. Las muestras fueron leídas y analizadas por Citometria de flujo FACSCalibur (B.D. Biosciences- San Diego, CA, USA).

\section{Resultados}

\section{Monocitos tratados por 72 horas con interleuquina 4 (IL-4) y factor estimulador de colonias granulocito/macrófago (GM-CSF) se diferencian eficientemente (CDi).}

Los monocitos aislados luego de 2 horas de incubación en cajas de petri de plástico, fueron cultivados durante 72 horas en presencia de IL-4 y GM-CSF. Culminado este tiempo, la expresión de marcadores de superficie fue evaluada mediante citometria de flujo. Es de resaltar que relacionado con la optimización del tiempo, este protocolo de generación de CDs en 72 horas es mucho más favorable (19), respecto al esquema convencional de derivación de células donde la exposición a las citoquinas inductoras de diferenciación oscila entre 5 y 7 días, antes de la maduración (20).

Entre los marcadores prototípicos bajo regulados durante la diferenciación de monocitos a CDs está el coreceptor CD14, cuya expresión disminuyó notablemente en CDs derivadas de monocitos luego de la incubación durante 72 horas en presencia del coctel de citoquinas utilizado como se muestra en la Figura 1. Adicionalmente y consistente con lo previamente reportado (21) las CDi expuestas a un potente inductor de maduración como el Poly I:C (22) expresan mínimas cantidades de este coreceptor a consecuencia de la completa diferenciación.

Otras moléculas como el CD209, CD80 y CD83 son sobre-expresadas por las CDs diferenciadas

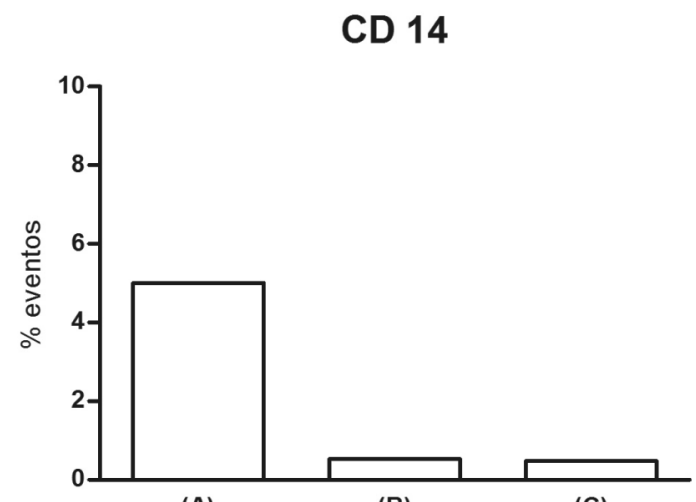

(A)

(B)

(C)

Figura 1. Diagrama representativo de la expresión del co-receptor CD14 determinada por citometria de flujo en monocitos, CDs tratadas durante 72 horas con IL-4 y GM-CSF. (A) Corresponde a monocitos; (B) CDs inmaduras y (C) CDs maduradas con Poly I:C. 
CD209

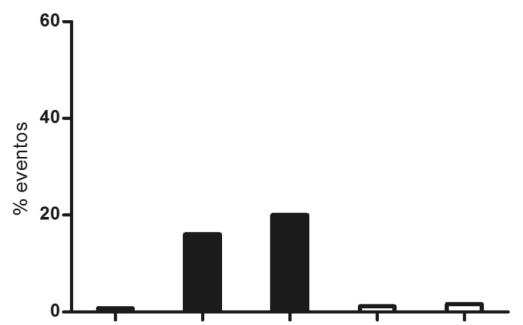

(A) (B)
(C)
(D)
(E)

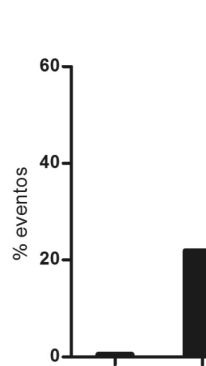

(A)
CD 80

(B)

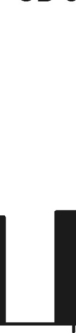

(C)

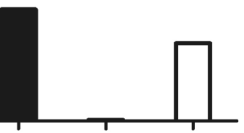

(D)

(E)

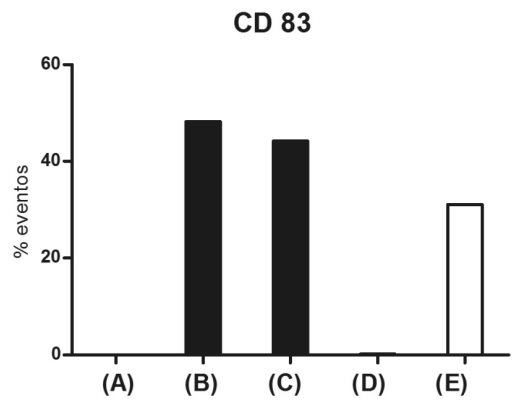

Figura 2. Diagrama representativo de la expresión de marcadores de superficie celular determinados por citometria de flujo. (A) Se refiere a la expresión en monocitos; ( $($ y $D$ ) expresión de marcadores en $C D i$ y ( $C$ y E) en CDm. Las barras oscuras corresponde a células dendríticas diferenciadas luego de 72 horas de cultivo en presencia de GM-CSF e IL-4; las barras sin relleno corresponden a las CDs obtenidas luego de 7 días de diferenciación.

comparativamente con los monocitos adherentes cultivados bajo las mismas condiciones en ausencia de GM-CSF e IL-4. Es importante recordar que todas las células provienen de un mismo individuo.

Acorde con nuestros resultados, la diferenciación en corto tiempo (72 horas) permite generar CDs más "competentes" a nivel de la expresión de moléculas co-estimuladoras, ya que como se observa en la Figura 2, incluso las CDi expresan un mayor porcentaje de moléculas como CD209, CD80 y CD83 aún respecto a CDs derivadas mediante el protocolo convencional y maduradas con Poly I:C. Es de resaltar, que CD209 no pudo ser detectado en CDs diferenciadas durante 7 días, quizá más por fallos técnicos como reducción del número de células viables (Datos no mostrados) que por razones inherentes a la expresión de la molécula en CDs. Figura 2.

A nivel de las diferencias fenotípicas propias reconocidas para las CDs, las CDi obtenidas mediante los dos protocolos expresaron menor cantidad de la molécula HLA-DR, la cual fue sobre-expresada luego de la inducción de la maduración lograda mediante el tratamiento con Poly I:C como se observa en la Figura 3.

\section{CDs diferenciadas luego de 72 horas de tratamiento con IL-4 y GM-CSF fueron exitosamente infectadas con promastigotes de L. panamensis.}

Las CDi obtenidas y los monocitos cultivados bajo las mismas condiciones fueron infectados con promastigotes de L. panamensis con el fin de determinar la capacidad de estas células de fagocitar el agente patógeno. Simultáneamente, se pretendió confirmar la modulación

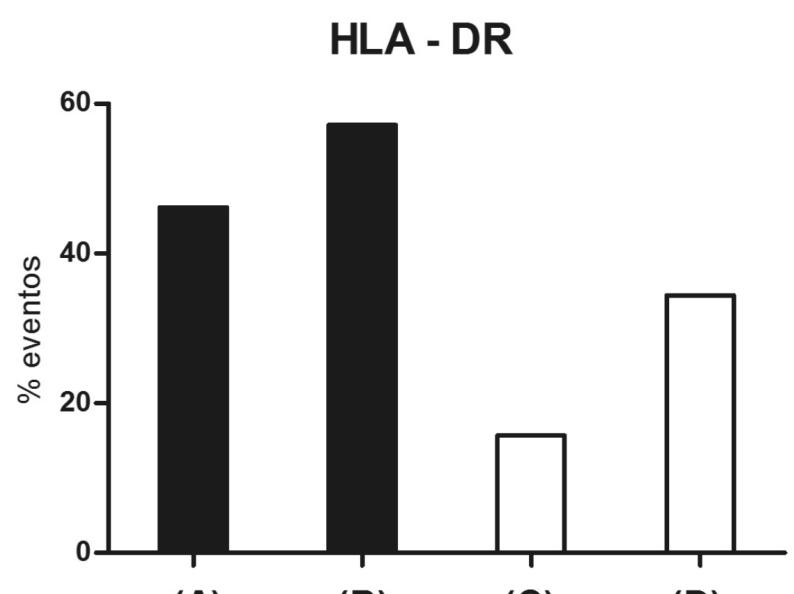

(A) (B)

(C)

(D)

Figura 3. Diagrama representativo de la expresión de la molécula HLADR en CDs determinada por citometria de flujo. $(A-C)$ corresponde a la expresión de HLA-DR en CDi y $(B-D)$ corresponde a la expresión de la molécula en CDm. Las barras oscuras referencia a CDs obtenidas luego de la diferenciación durante 72 horas en presencia del coctel de citoquinas y las barras claras hacen referencia a las CDs obtenidas mediante el protocolo convencional.

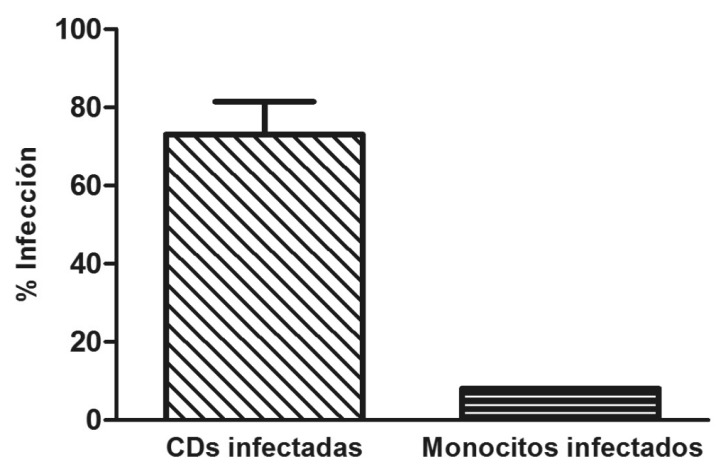

Figura 4. La grafica muestra el porcentaje de células infectadas con $L$. panamensis evaluado por observación microscópica. (A) Corresponde al porcentaje de infección en las CDs obtenidas y (B) al porcentaje de infección en monocitos. 


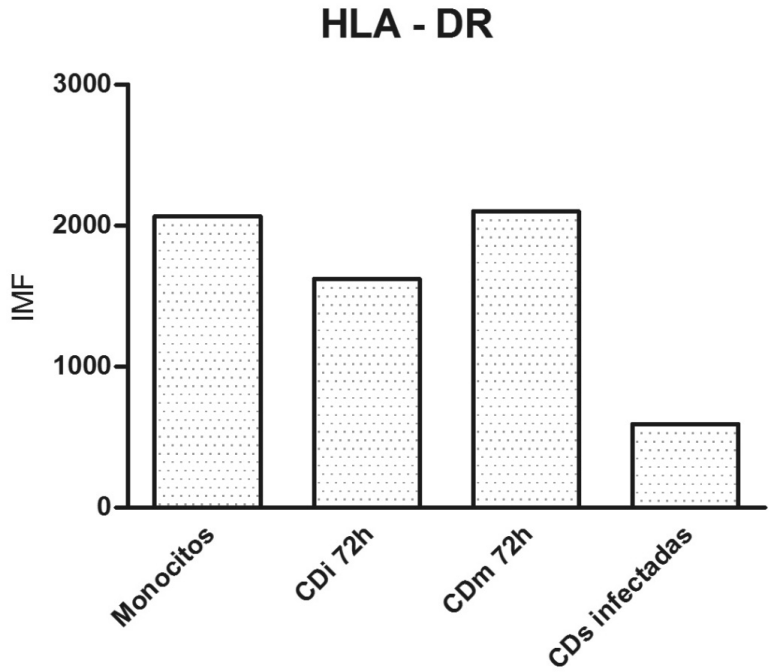

Figura 5. Diagrama representativo de la expresión de la molécula HLA-DR en monocitos y $C D$ s obtenidas en 72 horas sin infectar e infectadas con L. panamensis. (A) se refiere a la expresión de HLA-DR en Monocitos; (B) CD inmaduras; (C) CDs maduradas y (D) CDs infectadas.

que antígenos parasitarios inducían en la maduración y función de estas CPAs (23).

Las CDi obtenidas luego de 72 horas de diferenciación mostraron una superior capacidad de internalizar promastigotes en comparación con los monocitos obtenidos a partir de sangre periférica del mismo donador como se observa en la Figura 4.

\section{La infección por L. panamensis modula la respuesta inmune en monocitos y CDs derivadas de monocitos in vitro.}

La infección por L. panamensis bajo-regula la función de la presentación antigénica en CDs, modulando de esta manera, la consecuente respuesta inmune $\mathrm{T}$ helper generada frente a este patógeno.

Se observó que la expresión de la molécula HLA-DR en CDi infectadas fue suprimida en comparación con los monocitos y CDs maduras que no habían tenido contacto con el parásito, Figura 5, confirmándose de este modo que la modulación de la respuesta inducida sobre las CPA por antígenos de Leishmania se constituye en un seguro mecanismo de evasión parasitaria (18). Figura 5.

Así mismo, se evidenció esta modulación en la liberación de citoquinas asociadas con el proceso inflamatorio luego de la infección celular con L. panamensis, Figura 6.

La liberación de IL1 $\beta$, IL-8 e IL-10 fue superior en $\mathrm{CDi}$, respecto a los monocitos sin infectar lo cual sugiere una probable activación basal secundaria a las
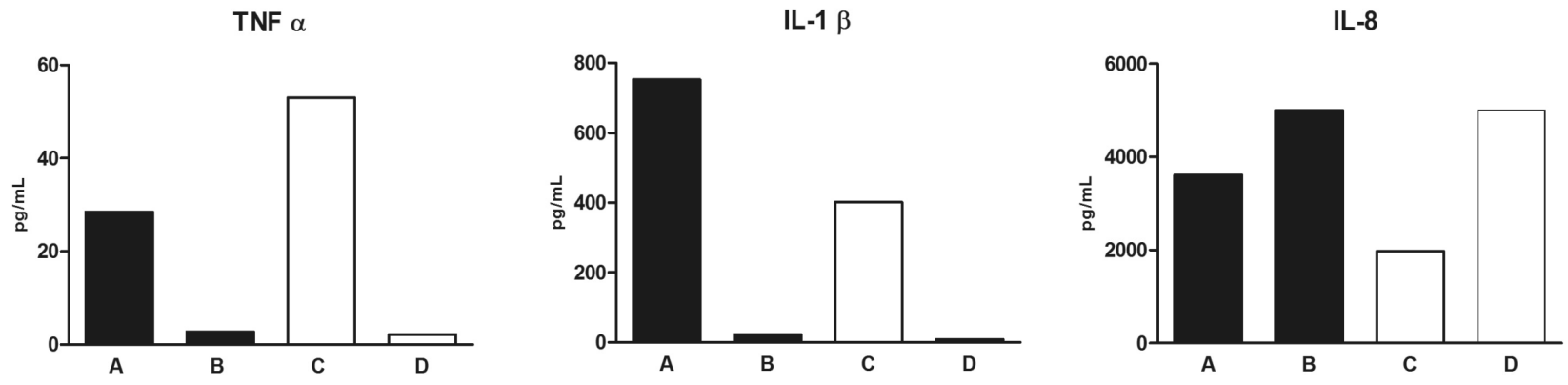

IL-10

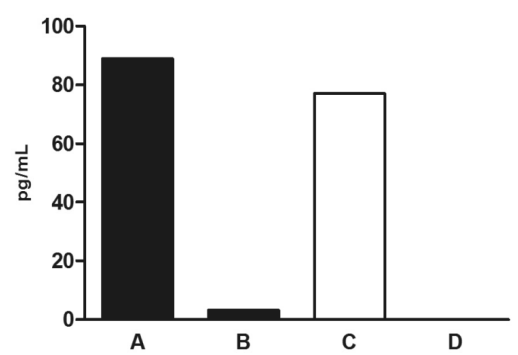

IL-6

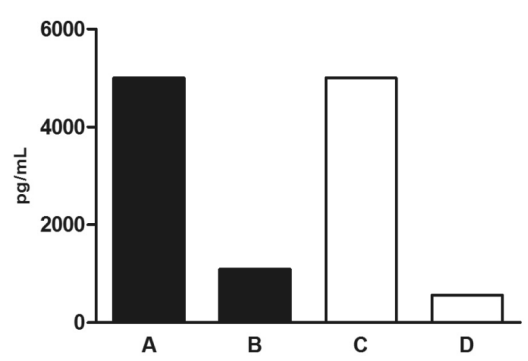

Figura 6. Diagrama representativo del perfil de citoquinas secretadas por CPAs infectadas con L. panamensis. (A) CDi sin infectar; (B) CDi infectadas con L. panamensis; (C) Monocitos sin infectar infectados y (D) Monocitos infectados con L. panamensis. 
condiciones propias de la manipulación y cultivo in vitro. La secreción de IL- 6 fue proporcionalmente equitativa en CDi y monocitos sin infectar, mientras que el TNF- $\alpha$ fue liberado en mayor cantidad por los monocitos libres de parásito. La secreción de todas las citoquinas monitoreadas (excepto IL-8) fue casi eliminada como consecuencia de la internalización del parásito y subsecuente inducción de una "parálisis" de la maquinaria de las CPAs por antígenos parasitarios. El único mediador liberado en mayor cantidad de forma específica por las CPAs luego de la infección por Leishmania fue la IL-8.

\section{Discusión}

Nosotros demostramos que CDs inmaduras diferenciadas durante 72 horas de cultivo en presencia de IL-4 y GM-CSF pueden ser utilizadas exitosamente en el estudio de agentes anti-leishmaniales, como un modelo in vitro efectivo para la caracterización de la respuesta generada frente a este patógeno, así como para la evaluación de la actividad inmuno-moduladora de nuevas formulaciones terapéuticas para el control de esta enfermedad. Las CDs pueden ser obtenidas in vitro a partir de diversas metodologías (15) y pueden ser empleadas como un modelo mucho más fiable para describir sustancias antiparasitarias intracelulares, que cuando se emplean otros tipos de modelos celulares.

En este estudio, los monocitos cultivados con IL-4 y GM-CSF se diferenciaron a CDs de fenotipo inmaduro, presentado características fenotípicas y funcionales típicas de esta población. Observamos que luego de 72 horas de cultivo la expresión del co-receptor CD14 disminuyó notablemente en las CDs obtenidas, mientras que se detectó un aumento en la expresión de moléculas coestimulatorias y en la actividad fagocítica en comparación de los monocitos. Este protocolo, además de disminuir el tiempo para la obtención de CDs en comparación con protocolos convencionales, también reduce la manipulación que luego de un prolongado cultivo puede conllevar a la afectación de la viabilidad y función de este tipo celular $(5,19)$.

Así mismo, se pudo observar que la infección con promastigotes de L. panamensis modula la respuesta inmune generada por parte de monocitos y CDs derivadas de monocitos. Las CPAs infectadas presentaron una supresión en la expresión de la molécula HLA-DR, así como una disminución en la secreción de TNF- $\alpha$, IL$1 \beta$, IL-8, IL-6 e IL-10, lo que puede estar asociados a un mecanismo utilizado por el parásito para retardar el desarrollo de una respuesta inmune especifica (24), bajoregulando la presentación antigénica en las CPAs.

Igualmente, reportamos que el aumento en la liberación de IL-8 en las células infectadas [una citoquina pro-inflamatoria con actividad quimiotactica para células polimorfonucleares $(\mathrm{PMN})]$, puede relacionarse con el proceso de reclutamiento de células en el sitio de la lesión. Estos datos, se correlacionan con lo reportado por otros grupos $(25,26)$, donde esta IL-8 junto con MCAF (factor activador - quimiotactico de monocitos) y MIP-1 (Proteína Inflamatoria de Macrofagos $1-\alpha$ y $\beta$ ) juegan un papel fundamental en el reclutamiento de células polimorfonucleares y monocitos (gracias a sus propiedades quimiotácticas), durante la infección por Leishmania, demostrándose que las CPAs infectadas, parecen ser activadas selectivamente por este patógeno como una posible estrategia para asegurar su supervivencia y replicación en la fase temprana de la infección (Un posible mecanismo de evasión asociado con modulación de la respuesta del hospedero).

Sugerimos el empleo de CDs infectadas como una aproximación experimental ideal para el tamizaje de sustancias con potencial actividad leishmanicida, debido a sus propiedades similares a lo reportado in vivo y por ende a una más factible extrapolación de los resultados al modelo humano.

\section{Agradecimientos}

Expresamos nuestros más sinceros agradecimientos a todos los integrantes del Grupo de Investigación en Inmunotoxicología del Departamento de Farmacia de la Facultad de Ciencias. Agradecemos de manera especial a la compañía Becton Dickinson de Colombia por facilitarnos el uso del Citómetro de flujo en calidad de apoyo tecnológico y a la docencia. Este proyecto pudo ser realizado con los recursos asignados por la Dirección de Investigación sede Bogotá (DIB), Universidad Nacional de Colombia (Proyecto aprobado No. 20201009461) y Colciencias-Instituto Colombiano para el desarrollo de la Ciencia y la Tecnología "Francisco José de Caldas" a través del proyecto 110140820378 . 


\section{Referencias}

1. WHO. Neglected tropical diseases, hidden successes, emerging opportunities 2006.

2. INS. (Ministerio de la Protección Social. Dirección General de Salud Pública Instituto Nacional de Salud. Subdirección de Vigilancia y Control en Salud Pública). Situacion de la leishmaniasis en Colombia, semanas epidemiologicas $1-52$ de 2007. 2008

3. King RJ, Campbell-Lendrum DH, Davies CR. Predicting geographic variation in cutaneous leishmaniasis, Colombia. Emerg Infect Dis. 2004;10: 598-607.

4. Murray HW, Berman JD, Davies CR, Saravia NG. Advances in leishmaniasis. Lancet. 2005;366:1561-1577.

5. Moll H. Dendritic cells as a tool to combat infectious diseases. Immunol Lett. 2003;85:153-157.

6. Palucka K, Banchereau J. How dendritic cells and microbes interact to elicit or subvert protective immune responses. Curr Opin Immunol 2002;14:420-431.

7. Banchereau J, Steinman RM. Dendritic cells and the control of immunity. Nature. 1998;392:245-252.

8. Liu YJ, Kanzler H, Soumelis V, Gilliet M. Dendritic cell lineage, plasticity and cross-regulation. Nat Immunol. 2001;2:585-589.

9. Mellman I, Steinman RM. Dendritic cells: specialized and regulated antigen processing machines. Cell. 2001;106:255-258.

10. Liu YJ. Dendritic cell subsets and lineages, and their functions in innate and adaptive immunity. Cell. 2001;106:259-262.

11. Lipscomb MF, Masten BJ. Dendritic cells: immune regulators in health and disease. Physiol Rev. 2002;82:97-130.

12. Banchereau J, Briere F, Caux C, Davoust J, Lebecque S, Liu YJ, Pulendran B, Palucka K. Immunobiology of Dendritic Cells. Annu Rev Immunol. 2000;18:767-811.

13. Kapsenberg ML. Dendritic-cell control of pathogen-driven T-cell polarization. Nat Rev Immunol. 2003;3:984-993.

14. Curfs JH, Meis JF, Hoogkamp-Korstanje JA. A primer on cytokines: sources, receptors, effects, and inducers. Clin Microbiol Rev. 1997;10:742-780.
15. Leon B, Lopez-Bravo M, Ardavin C. Monocyte-derived dendritic cells. Semin Immunol. 2005;17:313-318.

16. Moll H. Dendritic cells and host resistance to infection. Cell Microbiol. 2003;5:493-500.

17. Scott $P$, Hunter CA. Dendritic cells and immunity to leishmaniasis and toxoplasmosis. Curr. Opin. Immunol. 2002;14:466-470.

18. Sacks D, Sher A. Evasion of innate immunity by parasitic protozoa. Nat Immunol. 2002;3:1041-1047.

19. Dauer M, Obermaier B, Herten J, Haerle C, Pohl K, Rothenfusser S, Schnurr M, Endres S, Eigler A. Mature dendritic cells derived from human monocytes within 48 hours: a novel strategy for dendritic cell differentiation from blood precursors. J Immunol. 2003;170:4069-4076

20. Sallusto F, Lanzavecchia A. Efficient Presentation of Soluble Antigen by Cultured Human Dendritic Cells Is Maintained by Granulocyte/Macrophage Colony-stimulating Factor Plus Iuterleukin 4 and Downregulated by Tumor Necrosis Factor alfa. J Exp Med 1994;179:1109-1118.

21. Delgado G, Parra-López CA, Vargas LE, Hoya R, Estupiñán M, Guzmán F, Torres A y col. Characterizing cellular immune response to kinetoplastid membrane protein-11 (KMP-11) during Leishmania (Viannia) panamensis infection using dendritic cells (DCs) as antigen presenting cells (APCs). Parasite Immunol. 2003;25:199-209.

22. Rouas R, Lewalle P, Ouriaghli F, Nowak B, Duvillier H, Martiat P. Poly(I:C) used for human dendritic cell maturation preserves their ability to secondarily secrete bioactive IL-12. Int. Immunol. 2004;16:767-773

23. Kima PE. The amastigote forms of Leishmania are experts at exploiting host cell processes to establish infection and persist. Int J Parasitol. 2007;37: 1087-1096.

24. Matte C, Olivier M. Leishmania- Induced Cellular Recruitment during the Early Inflammatory Response: Modulation of Proinflammatory Mediators. J Infect Dis. 2002;185:673-681.

25. Dasgupta B, Roychoudhury K, Ganguly S, Akbar M, Das P, Roy S. Infection of Human Mononuclear Phagocytes and MacrophageLike THP1 Cells with Leishmania donovani Results in Modulation of Expression of a Subset of Chemokines and a Chemokine Receptor. Scand J Immunol. 2002;57:366-374.

26. Badolato R, Sacks D, Savoia D, Musso T. Leishmania major: Infection of Human Monocytes Induces Expression of IL-8 and MCAF. Exp Parasitol. 1996;82:21-26. 